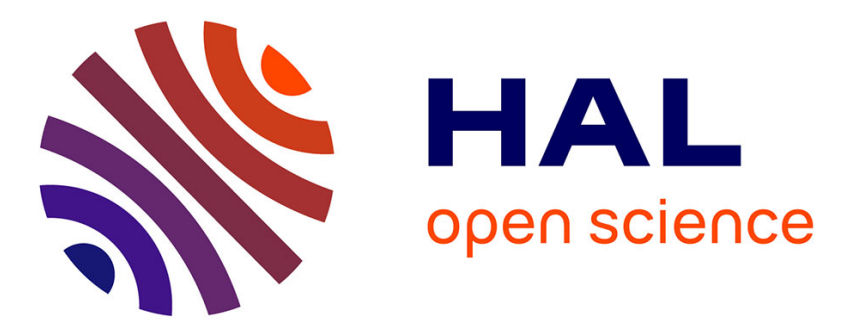

\title{
High reproducibility of two-dimensional liquid chromatography using pH-driven fractionation with a pressure-resistant electrode.
}

\author{
Elsa Suberbielle, Daniel Gonzales-Dunia, Frédéric Pont
}

\section{To cite this version:}

Elsa Suberbielle, Daniel Gonzales-Dunia, Frédéric Pont. High reproducibility of two-dimensional liquid chromatography using $\mathrm{pH}$-driven fractionation with a pressure-resistant electrode.: High reproducibility of two-dimensional liquid chromatography using $\mathrm{pH}$-driven fractionation with a pressure-resistant electrode.. Journal of Chromatography B - Analytical Technologies in the Biomedical and Life Sciences, 2008, 871 (1), pp.125-9. 10.1016/j.jchromb.2008.06.043 . inserm-00369925

\section{HAL Id: inserm-00369925 https://www.hal.inserm.fr/inserm-00369925}

Submitted on 23 Mar 2009

HAL is a multi-disciplinary open access archive for the deposit and dissemination of scientific research documents, whether they are published or not. The documents may come from teaching and research institutions in France or abroad, or from public or private research centers.
L'archive ouverte pluridisciplinaire HAL, est destinée au dépôt et à la diffusion de documents scientifiques de niveau recherche, publiés ou non, émanant des établissements d'enseignement et de recherche français ou étrangers, des laboratoires publics ou privés. 


\section{High reproducibility of two-dimensional liquid chromatography}

\section{separation of intact proteins using $\mathrm{pH}$-driven fractionation with a}

\section{pressure-resistant electrode}

Elsa Suberbielle ${ }^{1}$, Daniel Gonzalez-Dunia ${ }^{1}$ and Frédéric Pont ${ }^{2^{*}}$

1,2 INSERM, U563, Toulouse, France; ',2 Université Paul-Sabatier, Toulouse, France;

²Plateau Technique de Spectrométrie de Masse, Institut Claude de Préval (IFR30), Toulouse, France.

10 *To whom correspondence should be addressed: Service de Spectrométrie de Masse de I'IFR30, Bât B Pavillon Lefèbvre, CHU Purpan, BP 3028, 31024 Toulouse Cedex 3, France. Phone: +33 56274 8398; Fax: +33 56274 8384; Email: frederic.pont@toulouse.inserm.fr

15 Running title: two-dimensional liquid chromatography reproducibility in proteomics 
The abbreviations used are: 2D-LC, two-dimensional liquid chromatography; 2-DE, two-dimensional gel electrophoresis; HPLC, high performance liquid 20 chromatography; MS, mass spectrometry; HPCF, high performance chromatofocusing; RPHPLC, reverse phase high performance liquid chromatography; NPS, non-porous silica; ACN, acetonitrile; TFA, tri-fluoro-acetic acid. 


\section{Abstract}

Two-dimensional liquid chromatography using the PF2D system from Beckman Coulter is increasingly used in proteomics to provide an automated fractionation platform and to circumvent some limitations of fractionation using 2-D

30 electrophoresis. To date, the reliability and reproducibility of the PF2D fractionation procedure has not been formally tested. Here, we used an optimized software and a pressure-resistant $\mathrm{pH}$ electrode, allowing a precise and reproducible control of the $\mathrm{pH}$ limits for each fractions. We tested the reliability of this improved system by performing several rounds of PF2D using aliquots of the same protein extract. Three

35 UV maps were generated, leading to 54 chromatograms and more than 3000 protein peaks. We used a semi-automated software tool for peak-to-peak comparison between 2D-LC fractionation experiments to provide an accurate measurement of the reproducibility. The mean peak concordance was very high. The rates of concordance were higher in the second dimension repeatability tests, indicating that

40 the limiting factors in 2D-LC reproducibility rely in the $\mathrm{pl}$ fractionation and sample preparation steps. The reproducibility between maps was closely related to $\mathrm{pH}$ curves 
similarities, further stressing the need of careful $\mathrm{pH}$ adjustment and precise electrode calibration. Combined with good laboratory practice, 2D-LC using the PF2D system is a reproducible fractionation platform well suited for differential proteomics. 


\section{Introduction}

One of the main challenges in proteomics centers on the ability to generate a reproducible fractionation of the protein samples. Indeed, the discovery of novel

50 biomarkers, together with studies of disease pathogenesis, such as for cancer, rely on differential proteomics i.e., on the accurate comparison between control and pathological situations (1). Although the resolution and speed of mass spectrometers have been significantly improved these recent years, protein fractionation still represents a limiting step in a proteomic study. Indeed, it has been shown that the

55 improvement of the fractionation step significantly increases the number of proteins that can be subsequently analyzed by a mass spectrometer, thereby resulting in a dramatic increase of the dynamic range of an analysis (2). To date, there is no single fractionation strategy that has demonstrated the capacity to cover the whole proteome, but several complementary approaches are now available. Protein

60 fractionation has been traditionally performed using 2-DE. However, this franctionation method exhibits several limitations. It often restricts the analysis to the most abundant proteins, has demonstrated a relative lack of reproducibility and has trouble resolving proteins of extreme hydrophobicity, mass or isoelectric point (pl) (3, 4). To circumvent these limitations and to provide an alternative to 2-DE, liquid-based 
$652 \mathrm{D}$ liquid chromatographic (2D-LC) systems have been developed (5). The recent availability of an automated system based on 2D-LC, the Proteome-Lab ${ }^{\mathrm{TM}}$ PF2D from Beckman Coulter, facilitates the effective implementation of a 2D-LC experiment. The PF2D system separates proteins in the first dimension according to their pl using chromatofocusing, followed by a fractionation according to hydrophobicity, using

70 reversed phase chromatography in the second dimension. The pl-based fractionation, as performed during the first dimension of the PF2D (and in 2-DE), has been shown to be especially useful to study proteins post-translational modifications, such as phosphorylation (6). Several recent proteomic studies comparing the different available fractionation strategies have shown that the different technologies

75 are highly complementary, with a remarkably low number of common proteins identified by all technologies $(7,8)$. However, it seems clear that 2D-LC allows the identification of more proteins than 2D-gels and may be more suited for novel protein discovery $(7,8)$.

Automated 2D-LC fractionation, such as that provided by the PF2D system, is

80 relatively new and the reliability and reproducibility of this fractionation procedure remains to be formally assessed and quantified accurately. It was shown that PF2D could generate relatively reproducible UV profiles, based on the visual examination of the chromatograms (9-11). However, a certain level of variability was due to the 
dynamic nature of the pl fractionation in the first dimension fractionation. As a result,

85 the $\mathrm{pH}$ limits of the fractionation gradient could not be fixed, leading sometimes to small shifts in fractionation. In this work, we present a systematic assessment of the reproducibility of PF2D fractionation, using an improved methodology for the first dimension fractionation. We used a software patch, ensuring that all fractionation experiments would start at the exact same $\mathrm{pH}$ value. In addition, we used a prototype

$90 \mathrm{pH}$ electrode allowing the accurate $\mathrm{pH}$ measurement under pressure. We tested the reliability of this improved system by performing several rounds of PF2D fractionation using aliquots of the same protein extract. We used a semi-automated software tool for peak-to-peak comparison between 2D-LC fractionation experiments, facilitating the systematic analysis of more than 3000 peaks. We provide herein the first formal

95 demonstration of the high level of reproducibility of PF2D fractionation, which underscores the interest of this fractionation method for studies of differential proteomics. 


\section{Experimental}

Cell cultures - Vero E6 cells (ATCC CRL-1586) were grown to confluence in DMEM (Gibco-Invitrogen), supplemented with 10\% heat-inactivated fetal calf serum (PAA) and 1 X Bufferall (Sigma-Aldrich). Cells $\left(140 \times 10^{6}\right)$ were harvested by scraping, washed once in Phosphate Buffered Saline (Invitrogen) and recovered by

105 centrifugation for $5 \mathrm{~min}$. at $430 \times \mathrm{g}$ at room temperature. Cell pellets were then resuspended in lysis buffer (ProteomeLab ${ }^{\text {TM }}$ PF2D, Beckman) containing a cocktail of protease inhibitors (Sigma-Aldrich) and lysis was performed according to the ProteomeLab $^{\mathrm{TM}}$ PF2D human cell lysis protocol. Protein concentration was determined using the 2D quant protein assay (Amersham, Biosciences, Piscataway,

$110 \mathrm{NJ}, \mathrm{USA}$ ). Aliquots of cell extracts were stored at $-80^{\circ} \mathrm{C}$ until ready for use.

Liquid chromatography - Prior to chromatofocusing, an aliquot of the cell extract was thawed, desalted on a PD-10 Sephadex ${ }^{\mathrm{TM}}$ G-25 gel filtration column with a 5 kDa cutoff (Amersham Biosciences, Piscataway, NJ, USA) and eluted using the chromatofocusing Start Buffer. $1.5 \mathrm{mg}$ of protein extract was used in each 2D-LC

115 experiment. 2D-LC was performed using the ProteomeLab ${ }^{\mathrm{TM}}$ PF2D Protein Fractionation System (Beckman Coulter, Fullerton, CA, USA), which consists of two 
HPLCs, two UV detectors, an auto sampler and a fraction collector. The first dimension fractionation of PF2D consists in chromatofocusing, based on charge. After collection of the fractions from the first dimension in the collector module, each

120 of them is automatically introduced into the second dimension reversed phase chromatography column, which separates proteins based on their hydrophobicity. The fractions can be finally collected into 96-deep-well plates.

Chromatofocusing was performed on an HPCF 1-D column $(250 \times 2.1 \mathrm{~mm}$, Beckman Coulter). This first dimension HPLC module was equipped with a $5 \mathrm{ml}$ sample loop.

125 The signal was recorded at $280 \mathrm{~nm}$. The $\mathrm{pH}$ gradient was generated using Start Buffer $(\mathrm{pH} 8.5)$ and Elution Buffer $(\mathrm{pH} 4)$, both included in the ProteomeLab ${ }^{\mathrm{TM}}$ PF2D kit. The chromatofocusing column was first equilibrated for 130 minutes with Start Buffer at $\mathrm{pH} 8.5$ at a flow rate of $0.2 \mathrm{ml} / \mathrm{min}$, before being loaded with $1.5 \mathrm{mg}$ of the desalted protein extract. The flow-through was collected and after a stable baseline

130 was established ( 35 minutes), a linear $\mathrm{pH}$ gradient was initiated by infusing the elution buffer for 95 minutes with a constant flow rate of $0.2 \mathrm{ml} / \mathrm{min}$. The proteins with a pl $<4$ were finally eluted by washing the column with $1 \mathrm{M} \mathrm{NaCl}$. A software patch (SP1 Beckman Coulter) was used to ensure that each fraction collection experiment would start at a $\mathrm{pH}$ value of 8.3 . Fraction collection from the first dimension was 135 controlled with an in-line $\mathrm{pH}$ meter equipped with a prototypic pressure-resistant $\mathrm{pH}$ 
electrode (replacement kit $\mathrm{p} / \mathrm{n}$ A48657). Fractions were collected every $10 \mathrm{~min}$, except during the $\mathrm{pH}$ gradient portion of the run, from $\mathrm{pH} 8.5$ to 4.0 , when fractions were collected at $0.3 \mathrm{pH}$ unit-intervals.

The second dimension analysis used a nonporous RPHPLC using a C18 column (4.6 $140 \times 33 \mathrm{~mm}$, Beckman Coulter) packed with $1.5 \mu \mathrm{m}$ non-porous silica and kept at $50^{\circ} \mathrm{C}$ in a heated column jacket. Eighteen fractions from the first dimension were injected in the NPS-C18 column and eluted using a water/acetonitrile gradient at $0.75 \mathrm{ml} / \mathrm{min}$. The injection volume was between 50 and $500 \mu \mathrm{l}$ depending on the protein concentration in the first dimension fraction. Solvent $A$ was $0.1 \%$ TFA in water and

145 solvent B was $0.08 \%$ TFA in ACN. The gradient consisted in $100 \%$ solvent A for 2 minutes, $0-100 \%$ solvent B for $30 \mathrm{~min}$ and $100 \%$ solvent B for 4 minutes. The UV signal was recorded a $214 \mathrm{~nm}$.

Chromatogram analysis - Chromatograms were integrated using the 32Karat software (Beckman Coulter, Fullerton, CA, USA). Data containing the surfaces and retention

150 times of the peaks were exported as a text file and a peak-to-peak analysis was performed using the 4.020 version of the GC-LC-concordance software (Spectrochrom, Bouc Bel Air, France. http://www.spectrochrom.com/). Briefly, this software converts the chromatograms into histograms and performs pair-wise comparisons. The software automatically finds the best quadratic equation to model 
155 the peak positions using the retention time tolerance and the equation order specified by the operator. A surface ratio between concordant peaks can also be calculated and used as a constraint to exclude peaks. The retention time tolerance was set to $5 \%$ and the surface of the peaks analyzed was set between $0.1 \%$ and $100 \%$ of the largest peak area. The percentage of concordance between the chromatogram A and

160 B was calculated as follows:

$\%$ concordance $=$ (number of peaks in chromatogram A concordant with chromatogram B x 100) / (total number of peaks in chromatogram B) In addition to the peak-to-peak analysis using the GC-LC-concordance software, each concordant peak was visually examined and validated. When required, some

165 peaks were manually integrated, in particular when a shoulder was not correctly detected by the automated analysis. 


\section{Results and discussion}

170 Sample preparation: the procedure used for sample preparation is an important parameter that can drastically affect reproducibility and is particularly important during the design of a differential proteomic study. For our repetitive 2D-LC maps, we prepared aliquots of the same cellular extract that were stored in the lysis buffer at $-80^{\circ} \mathrm{C}$, to limit the risks of protein degradation. The simultaneous preparation of the

175 cellular extracts for all repetitive PF2D rounds allowed us to ensure that any residual proteolysis occurring during the lysis procedure would be similar for all experiments, thereby limiting the addition of another variable in the analysis. However, the last steps of desalting/gel filtration of the sample were performed prior to each fractionation experiment, to match the conditions of a differential proteomic study, in

180 which these steps are mandatory and could be responsible for a decrease in reproducibility.

Chromatofocusing fractionation: One of the limitations of the chromatofocusing step in the PF2D system is the difficulty to precisely control the $\mathrm{pH}$ gradient from one run to another. Although the fraction collector is triggered by an online $\mathrm{pH}$ meter, there is

185 still a significant level of variability, due to the difficulty to measure accurately a pH 
value under pressure. Indeed, the $\mathrm{pH}$ electrode has been designed to detect accurately $\mathrm{pH}$ changes, but not necessarily to record precise $\mathrm{pH}$ values. As a result, the repeatability of this fractionation step is completely dependent on the repeatability of the $\mathrm{pH}$ gradients. In addition, the $\mathrm{pH}$ limits of the fractions are not exactly similar 190 between maps, which further complicates the analysis. In this work, we have implemented two significant improvements to the PF2D chromatofusing step. First, we used a novel prototypic electrode ( $\mathrm{p} / \mathrm{n} \mathrm{A} 48657)$ that has been designed not only to accurately measure changes in $\mathrm{pH}$, but also to give accurate $\mathrm{pH}$ measurements under pressure. With this new electrode, the $\mathrm{pH}$ value under pressure was $8.51 \pm$

1950.01 at the beginning of the gradient for all three experiments (Figure 1). This $\mathrm{pH}$ value measured at a calibrated bench $\mathrm{pH}$ meter was 8.55 , indicating that the accuracy of the measurements under pressure is in the range of $0.04 \mathrm{pH}$ units. Second, we used a software patch, which enables the fractions to start precisely at pH 8.30 for each experiment. Consequently, the $\mathrm{pH}$ limits for each fraction are exactly

200 the same between experiments (Figure 1), provided that the collection volume is not limiting. As a matter of fact, we increased the collecting time to 10 minutes, because we observed that the volume could be limiting for some fractions of the gradient with the usually recommended collecting time of $8.5 \mathrm{~min}$. Indeed, reproducibility was improved when comparing a collecting time of 10 minutes and 8.5 minutes (data not 
205 shown).

Chromatogram concordance analysis: A total of 54 chromatograms were generated, representing more than 3000 peaks. In order to assess accurately the reproducibility of the chromatograms with such a large amount of data, we performed a peak-topeak analysis using a modified version of the GC-LC-concordance software. This

210 software enables the comparison of two histograms obtained after peak integration of the chromatograms (Figure 2). The software uses a mathematical model and the retention time error to determine the theoretical position of a peak (see methods).

Second dimension repeatability: the repeatability of the second dimension is an important parameter to test because it gives the theoretical limit of the repeatability of

215 the 2D-LC experiment. To test for the second dimension repeatability, the same series of first dimension fractions were used several times for a second dimension fractionation. The use of a C18 NPS column in association to a UV detector at 214 $\mathrm{nm}$ enables the detection of proteins in the nanogram up to the microgram range (13). For this reason the chromatograms were analyzed with a dynamic range of $10^{3}$.

220 When testing the reproducibility of a simple chromatogram containing about 30 peaks, the peak concordance between chromatograms was 100\% (Figure 3A).

The most complex chromatogram of a 2D-LC experiment is generally obtained with 
the fraction of basic proteins $(\mathrm{pl}>8.5)$ not retained by the column. We injected this fraction in triplicate onto the NPS column and we obtained chromatograms of about 22580 peaks (Figure 3B). With these complex chromatograms, the peak concordance between chromatograms was $96.76 \pm 0.98 \%(n=3)$.

The lower concordance rate for complex chromatograms may be due to different factors. First, it is important to note that most of the peaks are not well resolved in these complex chromatograms. Indeed, MS analysis of 2D-LC peaks has shown that

230 most of the peaks are in fact composed of a mixture of proteins. A large peak can contain 10,20 or even more proteins. Therefore, the peak integration of such chromatograms is a critical step, since a small change in a shoulder slope can be responsible for a different integration of the same peak between two chromatograms. As a result, the same peak will be split into two peaks in one case and not in the 235 other, creating a mismatch immediately detected during the software processing of the chromatograms. Second, this decreased concordance rate may be the result of local deformations of the chromatograms, due to slight variations in the ACN gradient between experiments. An example of these local deformations is shown on Fig 3B, where we observed that the first peaks of the top chromatogram had a slightly higher

240 retention time than the 2 other chromatograms. While not globally affecting the rest of the chromatogram, this nevertheless impacted the resolution of peaks located at 
around $12 \min$ (Fig 3B).

In any event, the concordance rates remained remarkably high, and our results indicate that the second dimension is repeatable enough to detect small changes in

245 peak intensities.

$2 D$ proteins maps: Three 2D maps were obtained after subjecting aliquots of the same protein extract to the whole PF2D fractionation procedure, including sample preparation. The maps were obtained with a starting protein amount of $1.5 \mathrm{mg}$. In some fractions, the protein amount was barely sufficient to obtain a good UV signal,

250 stressing the necessity of using at least $1.5 \mathrm{mg}$ of protein to obtain a satisfactory map when working with a whole proteome. A visual inspection of the maps revealed good similarities and the differential maps displayed peaks of small intensities, indicating a good reproducibility of the experiments (data not shown).

A peak-to-peak analysis of all chromatograms was performed, leading to an accurate

255 measurement of the reproducibility. Results of the map-to-map reproducibility are displayed in Table I.

When performing the overall analysis of the reproducibility between all three experiments, we concluded that the mean peak concordance was $90.19 \pm 4.26 \%$ ( $n=$ 54). It should be stressed that these values reflect faithfully the reproducibility of the 
260 whole fractionation procedure, including not only the two HPLC steps of 2D-LC but also the last steps of sample preparation, in particular the gel filtration step, and the potential impact of sample storage.

In order to explain the slight variations in reproducibility observed between the three performed experiments, we calculated the residual sum of squares (RSS) for each

265 couple of curves of the $\mathrm{pH}$ gradients. The RSS is an evaluation of the distance between two $\mathrm{pH}$ curves and we found that the RSS $(\# 1, \# 2)=6.7$, the RSS $(\# 2, \# 3)=$ 8.19 and the RSS $(\# 1, \# 3)=13.62$. Therefore, it appears that the most reproducible maps have also the most reproducible $\mathrm{pH}$ curves, further stressing the importance of this initial fractionation step and the interest of the improvements tested herein. In any

270 event, it remains clear that the reproducibility of a fractionation experiment using PF2D depends on several, non exclusive parameters: the reproducibility of the sample preparation and the effect of sample storage, the reproducibility of the $\mathrm{pH}$ curves during the fractionation and the reproducibility of the second dimension gradient. Our results indicate that the reliability of fractionation using PF2D is well

275 suited to perform an accurate differential proteomic study. It should nevertheless be kept in mind that this two-dimensional fractionation method will not permit the complete fractionation of all the proteins from a global cell extract and that the UV intensity of a peak reflects the signal of a mixture of proteins. However, the high level 
of reproducibility of the 2D maps, as demonstrated in this study, enables a quick

280 identification of the fractions in which an abundant protein is responsible for a UV change. In addition, when a subproteome is analyzed by 2D-LC, the resulting peaks are sharper and less coelution is observed (14). In most cases, a subsequent quantification strategy by MS will nevertheless be required to evaluate the amount of each protein individually, either at the level of the intact protein (15) or at the peptide

285 level after tryptic digestion (12).

\section{Conclusions}

Here, we provide the first comprehensive assessment of protein fractionation using PF2D, by performing a systematic peak-to-peak measurement of 2D-LC reproducibility. We took advantage of recent hardware and software improvements in

290 the chromatofocusing step of 2D-LC, in particular the use of a new pH electrode giving accurate measurements under pressure combined with a software modification enabling a fractionation based on fixed $\mathrm{pH}$ values. Our results demonstrate the high level of reproducibility of the PF2D system, indicating its suitability for differential proteomic studies. 


\section{Acknowledgements}

This work was supported by grants from INSERM, from Région Midi-Pyrénées, from the Genopôle and Canceropôle Grand-Sud-Ouest and from an ANR-06-

300 MIME-005-01 grant to DGD. ES is a recipient of a "poste d'accueil" from INSERM. DGD is supported by the CNRS.

The authors would like to acknowledge Beckman Coulter and especially Jerald S. Feitelson, Michael Simonian and Jeff Chapman for their support and for providing the prototype electrode and software patches. Raymond Loyer, from Spectrochrom, is

305 acknowledged for providing the GC-LC-concordance software and for his useful collaboration in the tuning of the mathematical parameters. 


\section{REFERENCES}

310 1. Monteoliva, L. and Albar, J.P. (2004) Differential proteomics: an overview of gel and non-gel based approaches. Brief Funct Genomic Proteomic 3, 220-239

2. Sheng, S., Chen, D. and Van Eyk, J.E. (2006) Multidimensional liquid chromatography separation of intact proteins by chromatographic focusing and reversed phase of the human serum proteome: optimization and protein database.

315 Mol. Cell Proteomics 5, 26-34

3. Issaq, H.J. and Veenstra, T.D. (2007) The role of electrophoresis in disease biomarker discovery. Electrophoresis 28, 1980-1988

4. Skalnikova, H., Halada, P., Dzubak, P., Hajduch, M. and Kovarova, H. (2005) Protein fingerprints of anti-cancer effects of cyclin-dependent kinase inhibition:

320 identification of candidate biomarkers using 2-d liquid phase separation coupled to mass spectrometry. Technol. Cancer Res. Treat. 4, 447-454

5. Lubman, D.M., Kachman, M.T., Wang, H., Gong, S., Yan, F., Hamler, R.L., O'Neil, K.A., Zhu, K., Buchanan, N.S. and Barder, T.J. (2002) Two-dimensional liquid separations-mass mapping of proteins from human cancer cell lysates. J.

325 Chromatogr. B Analyt. Technol. Biomed. Life Sci. 782, 183-196

6. Zhu, K., Zhao, J., Lubman, D.M., Miller, F.R. and Barder, T.J. (2005) Protein pl shifts due to posttranslational modifications in the separation and characterization of proteins. Anal. Chem. 77, 2745-2755

7. McDonald, T., Sheng, S., Stanley, B., Chen, D., Ko, Y., Cole, R.N., Pedersen, 
330 P. and Van Eyk, J.E. (2006) Expanding the subproteome of the inner mitochondria using protein separation technologies: one- and two-dimensional liquid chromatography and two-dimensional gel electrophoresis. Mol. Cell Proteomics 5, $2392-2411$

8. $\quad$ Li, X., Gong, Y., Wang, Y., Wu, S., Cai, Y., He, P., Lu, Z., Ying, W., Zhang, Y.,

335 Jiao, L., He, H., Zhang, Z., He, F., Zhao, X. and Qian, X. (2005) Comparison of alternative analytical techniques for the characterisation of the human serum proteome in hupo plasma proteome project. Proteomics 5, 3423-3441

9. Park, K.H., Lipuma, J.J. and Lubman, D.M. (2007) Comparative proteomic analysis of b. cenocepacia using two-dimensional liquid separations coupled with

340 mass spectrometry. Anal. Chim. Acta 592, 91-100

10. Soldi, M., Sarto, C., Valsecchi, C., Magni, F., Proserpio, V., Ticozzi, D. and Mocarelli, P. (2005) Proteome profile of human urine with two-dimensional liquid phase fractionation. Proteomics 5, 2641-2647

11. Yan, F., Subramanian, B., Nakeff, A., Barder, T.J., Parus, S.J. and Lubman,

345 D.M. (2003) A comparison of drug-treated and untreated hct-116 human colon adenocarcinoma cells using a 2-d liquid separation mapping method based upon chromatofocusing pl fractionation. Anal. Chem. 75, 2299-2308

12. Old, W.M., Meyer-Arendt, K., Aveline-Wolf, L., Pierce, K.G., Mendoza, A., Sevinsky, J.R., Resing, K.A. and Ahn, N.G. (2005) Comparison of label-free methods 350 for quantifying human proteins by shotgun proteomics. Mol. Cell Proteomics 4, 1487-1502

13. Dauly, C., Perlman, D.H., Costello, C.E. and McComb, M.E. (2006) Protein separation and characterization by np-rp-hplc followed by intact maldi-tof mass 
spectrometry and peptide mass mapping analyses. J. Proteome Res. 5, 1688-1700

355 14. Cussac, D., Pichereaux, C., Colomba, A., Capilla, F., Pont, F., Gaits-lacovoni, F., Lamant, L., Espinos, E., Burlet-Schiltz, O., Monsarrat, B., Delsol, G. and Payrastre, B. (2006) Proteomic analysis of anaplastic lymphoma cell lines: identification of potential tumour markers. Proteomics 6, 3210-3222

15. Zhao, J., Chang, A.C., Li, C., Shedden, K.A., Thomas, D.G., Misek, D.E.,

360 Giordano, T.J., Beer, D.G. and Lubman, D.M. (2007) Comparative proteomic analysis of barrett's metaplasia and esophageal adenocarcinomas using 2-d liquid mass mapping. Mol. Cell Proteomics 6, 987-999 


\section{Figure Legends}

365 Figure 1. Reproducibility of the pH gradients using the optimized PF2D system. $\mathrm{pH}$ gradients from experiments \#1(circles), \#2 (squares), \#3 (diamonds) generated during the chromatofocusing step. The gradients were generated inside the chromatofocusing column by injecting an eluent buffer at $\mathrm{pH} 4.0$ in the column, previously equilibrated with the start buffer at $\mathrm{pH}$ 8.5. Vertical dotted lines represent

370 the fractions limits, which start at $\mathrm{pH} 8.3$ and end at $\mathrm{pH}$ 4.0. The software patch SP1 enables fractions from each experiment to have exactly the same $\mathrm{pH}$ limits.

Figure 2. Comparative chromatogram analysis using the GC-LC-concordance software. Screenshot of one analysis output. The chromatograms were integrated

375 and converted into histograms, with bar lengths being proportional to the original peak surface. Two mirroring histograms are represented in black. Concording peaks are linked together by blue lines, while non-concording peaks are tagged with a red line. 
380 Figure 3. Representative examples of the repeatability of 2D-LC fractionation.

Top: protein UV $(214 \mathrm{~nm})$ profiles obtained after two injections of the same first dimension fraction ( $\mathrm{pH}$ 6.8-7.1) on a C18 NPS column. Inset: detail of the peak integration performed by the 32karat software for the analysis. The inset table shows the results of peak concordance.

385 Bottom: protein UV $(214 \mathrm{~nm})$ profiles obtained after three injections of the same first dimension fraction $(\mathrm{pH}>8.5)$ on a C18 NPS column. The inset table shows the results of peak concordance.

\section{Tables}

TABLE 1: Mean peak concordance between 2D maps (\%)

\begin{tabular}{llll}
\hline & Peak concordance & Map \#2 & Map \#3 \\
\hline Map \#1 & w/o & $91.59 \pm 3.99$ & $89.24 \pm 3.16$ \\
& \# of concording peaks & 1062 & 1067 \\
\hline Map \#3 & w/o & $89.76 \pm 5.24$ & $\mathrm{NA}^{1}$ \\
& \# of concording peaks & 1074 & $\mathrm{NA}^{1}$ \\
\hline
\end{tabular}

390

Results are expressed as mean \pm SD $(n=18)$. not applicable 
Figures

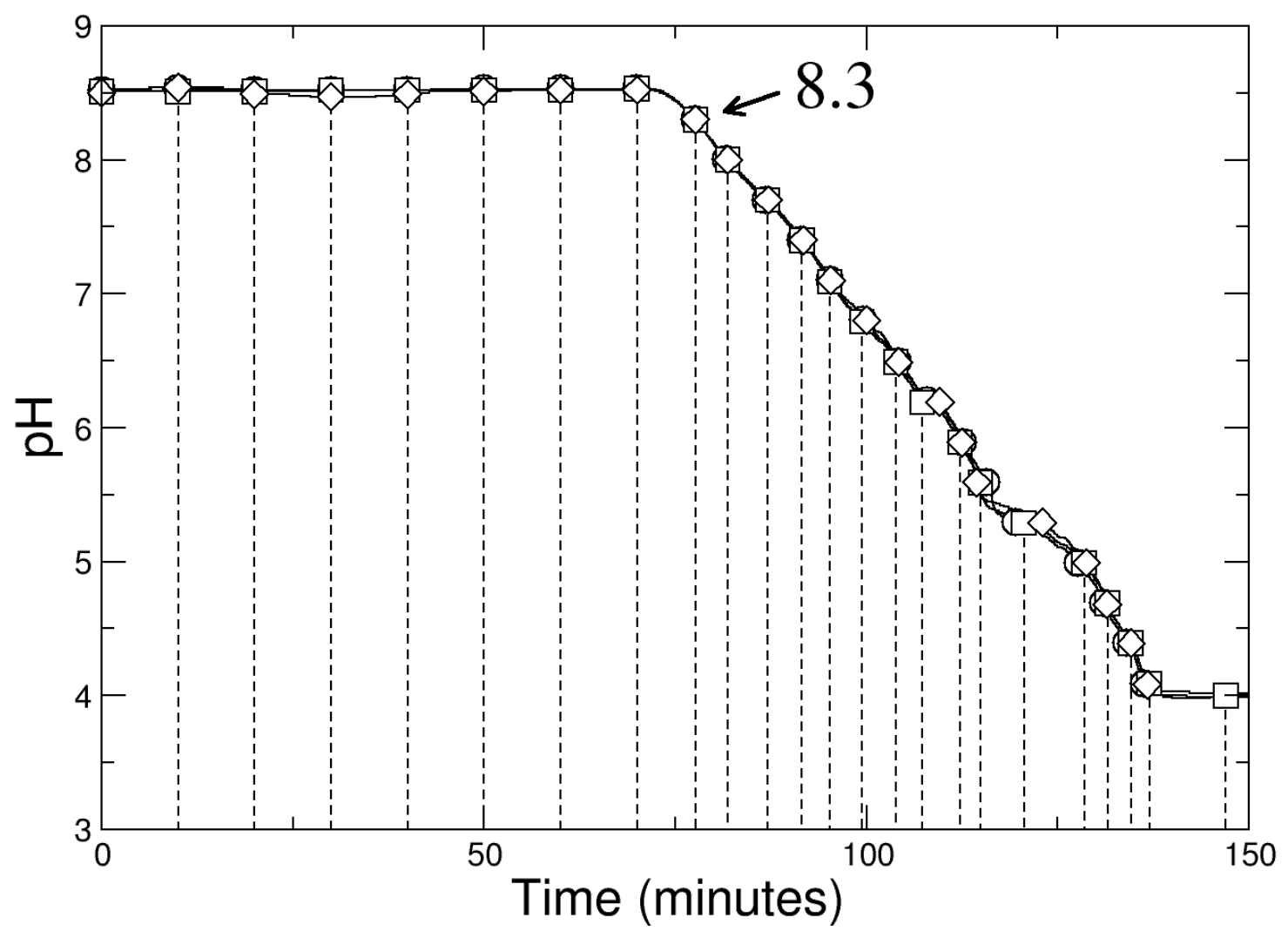

Figure 1. 


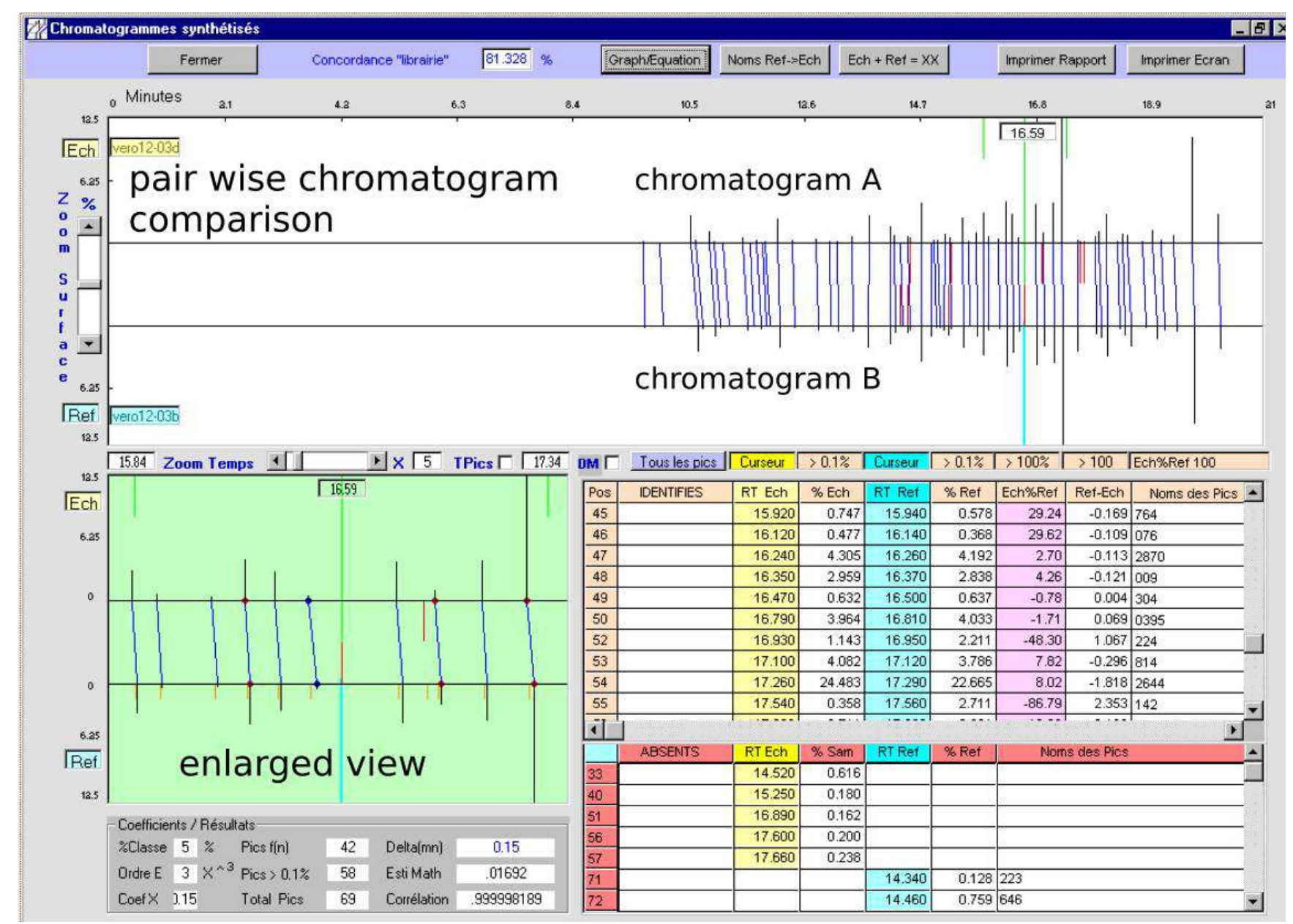

Figure 2. 

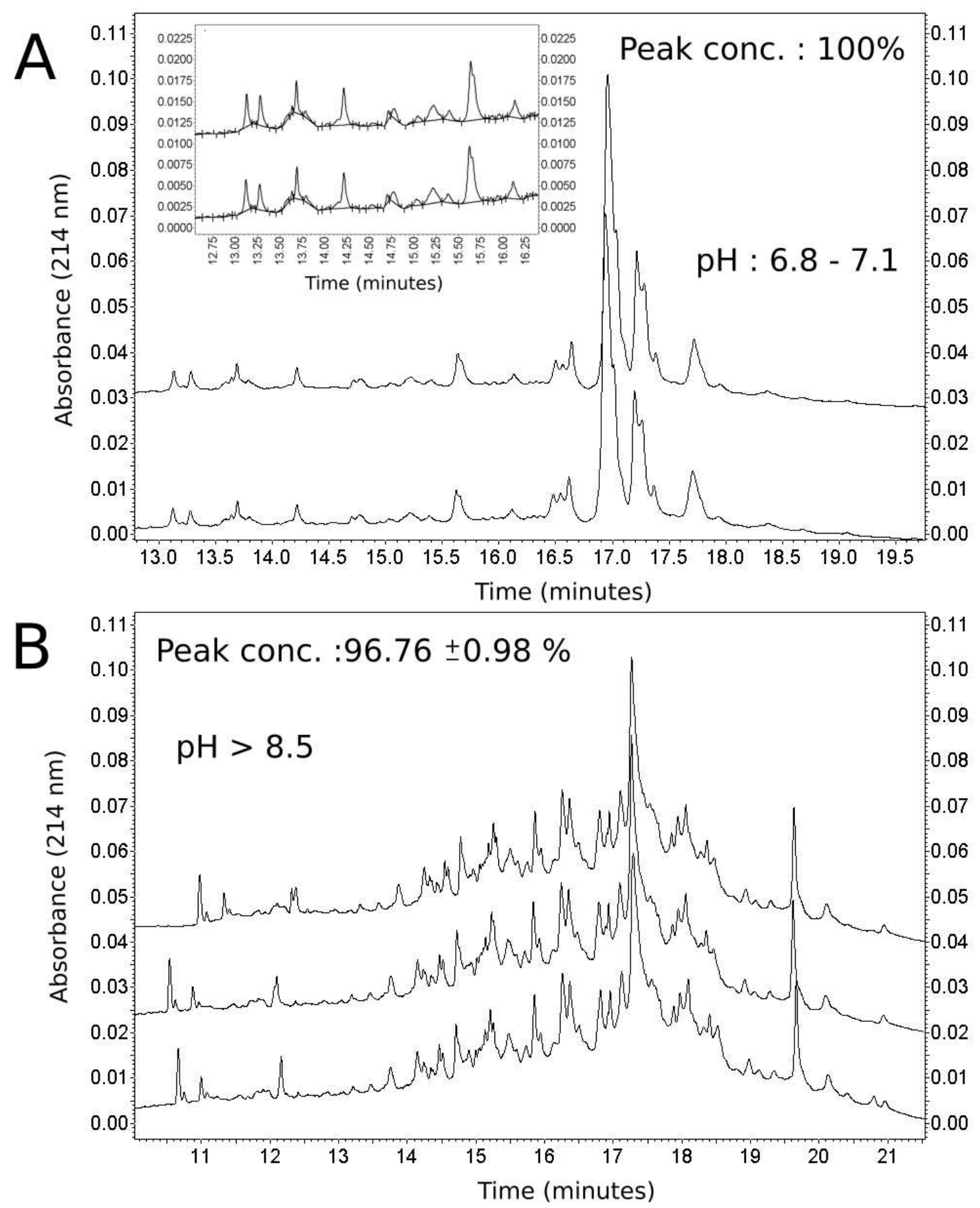

Figure 3. 